\title{
Editorial
}

\section{Laparoscopic surgery for GIST: too soon to decide}

\author{
Yoshinide Otani and Masaki Kitajima \\ Department of Surgery, Keio University School of Medicine, 35 Shinanomachi, Shinjuku-ku, Tokyo 160-8582, Japan
}

The management of gastrointestinal stromal tumors (GISTs) has evolved rapidly. Recently developed immunohistochemical staining methods allow the differentiation of GIST from myogenic, neurogenic, and other mesenchymal tumors [1]. A tyrosine kinase receptor antagonist, imatinib mesylate, has shown excellent results in patients with unresectable or metastatic GIST [2], but surgical resection of the primary tumor is the treatment of choice when cure is sought [3].

Although a conclusive randomized-controlled trial with a proper number of cases remains to be done, laparoscopic surgery for gastric cancer is now an accepted modality for curative surgery [4]. The goal of surgery for GIST is complete resection of visible and microscopic disease, avoiding capsule rupture and intra-abdominal spillage of tumor cells. As GIST rarely metastasizes to local regional lymph nodes, lymphadenectomy is warranted only for evident nodal involvement. These findings suggest that wedge resection with a clear surgical margin is the most suitable procedure for the surgical treatment of gastric GIST.

Laparoscopic surgery for GIST has been the subject of recent consensus meetings in the United States and Europe. The National Comprehensive Cancer Network (NCCN) task force report [5] states that "laparoscopic or laparoscopic-assisted resection may be used for small $(<2 \mathrm{~cm})$ GISTs when the risk of intraoperative tumor rupture is low. However, the use of laparoscopic resection is generally discouraged for GIST." Another report of the consensus meeting for the management of gastrointestinal stromal tumor under the auspices of the European Society of Medical Oncology (ESMO) [6] declares that "laparoscopic surgery should be avoided, owing to the higher risk of tumor rupture and subsequent peritoneal seeding. A laparoscopic resection

Offprint requests to: Y. Otani might be accepted in cases of small $(\leq 2 \mathrm{~cm})$ intramural tumors." According to these reports, laparoscopic surgery for GIST is recommended only for cases of very small size because of the risk of tumor cell seeding and subsequent peritoneal recurrence.

Laparoscopic surgery for gastric cancer has been widely adopted in Japan and other countries, including Korea, China, Italy, and the United States. Although the number of laparoscopic procedures for GIST represents only a tiny fraction of the total for gastric tumors, feasible results for laparoscopic wedge resection for GIST have been reported from major institutions $[7,8]$. At our institution, we resected 60 cases of gastric GIST from 1993 to 2003. Mean tumor size was $42.5 \mathrm{~mm}$ (range, 18-150 mm) and operative procedures were laparoscopic wedge resection for 35 cases, laparoscopyassisted surgery for 3 cases, and conventional open surgery for 22 cases. With a median follow-up period of 53 months, no local or peritoneal recurrence after curative surgery has been experienced. Avoiding capsule rupture and intra-abdominal spillage of tumor cells is clearly the most important point in GIST surgery, but this is equally true for not only laparoscopic but also conventional open surgery. Intracorporeal biopsy during surgery may cause the peritoneal seeding of tumor cells and should be avoided in GIST surgery. Gentle handling of the bulky mass wrapped with sterile gauze is also helpful for preventing tumor cell spillage. Most GISTs are hard and elastic and are coated with a thin capsule, but some are very fragile and bleed easily. These latter require particular attention to keeping the tumor capsule intact until resection with a clear margin is completed and the resected specimen is retrieved from the abdomen to the back table. If such unusual GISTs are encountered during laparoscopic surgery, the procedure should be switched to laparoscopyassisted or conventional open surgery immediately.

We have been generally satisfied with the results of wedge resection of small GISTs $(\leq 5 \mathrm{~cm})$ at our institu- 
tion [9]. However, as described by Yano and colleagues in their article in this issue [10], careful tactile handling and adequate traction of the tumor are necessary for the resection of large GISTs $(5 \mathrm{~cm}<\mathrm{T}<10 \mathrm{~cm})$. Hand-assisted laparoscopic surgery (HALS) may be suitable for this purpose. HALS was first described by Kusminsky and colleagues as allowing better vascular control in laparoscopic splenectomy [11], while Tanimura and colleagues described a series of HALS for gastric cancer in 2003 [12].

In Western countries, most GIST patients first present at an outpatient clinic with complaints of vague abdominal discomfort or anemia due to a large bulky GIST [13]. In Japan and some other Asian countries, however, asymptomatic incidental GIST is common and usually is detected in screening $[7,14]$. The negative perception of laparoscopic surgery for GIST may have arisen partly as a result of these background differences.

Only a decade has passed since the introduction of laparoscopic surgery for gastric tumors, and the concept of GIST is of even shorter duration. It is too early to reach any definitive conclusions. The etiology, biology, and optimum management of GIST remain largely unknown, and patients should be treated in a minimally invasive and appropriately careful manner.

\section{References}

1. Fletcher CD, Berman JJ, Corless C, Gorstein F, Lasota J, Longley BJ, et al. Diagnosis of gastrointestinal stromal tumors: a consensus approach. Hum Pathol 2002;33:459-65.

2. Kitamura Y, Hirota S, Nishida T. Gastrointestinal stromal tumors (GIST): a model for molecule-based diagnosis and treatment of solid tumors. Cancer Sci 2003;94:315-20.
3. DeMatteo RP, Heinrich MC, El-Rifai WM, Demetri G. Clinical management of gastrointestinal stromal tumors: before and after STI-571. Hum Pathol 2002;33:466-77.

4. Kitano S, Shiraishi N. Current status of laparoscopic gastrectomy for cancer in Japan. Surg Endosc 2004;18:182-5.

5. Demetri GD, Benjamin R, Blanke CD, Choi H, Corless C, Dematteo RP, et al. NCCN task force report: optimal management of patients with gastrointestinal stromal tumor (GIST) expansion and update of NCCN clinical practice guidelines. J Natl Compr Cancer Netw 2004;2(Suppl 1):S1-S26.

6. Blay JY, Bonvalot S, Casali P, Choi H, Debiec-Richter M, Dei Tos AP, et al. Consensus meeting for the management of gastrointestinal stromal tumors. Report of the GIST consensus conference of 20-21 March 2004, under the auspices of ESMO. Ann Oncol 2005;16:566-78.

7. Otani Y, Ohgami M, Igarashi N, Kimata M, Kubota T, Kumai K, et al. Laparoscopic wedge resection of gastric submucosal tumors. Surg Laparosc Endosc Percutan Tech 2000;10:19-23.

8. Carboni F, Carlini M, Scardamaglia F, Santoro E, Boschetto A, Castelli M, et al. Gastrointestinal stromal tumors of the stomach. A ten-year surgical experience. J Exp Clin Cancer Res 2003;22: 379-84.

9. Otani Y, Kitajima M. Current status of laparoscopic surgery for gastric cancer and GIST. In: Kuriyama S, Yoshiji H, editors. New perspectives in cancer research and therapy. Kerala (India): Signpost; 2005. p. 111-24.

10. Yano $\mathrm{H}$, Kimura $\mathrm{Y}$, Iwazawa $\mathrm{T}$, Takemoto $\mathrm{H}$, Imasato $\mathbf{M}$, Monden T, et al. Hand-assisted laparoscopic surgery for a large gastrointestinal stromal tumor of the stomach. Gastric Cancer 2005;8:186-92.

11. Kusminsky RE, Boland JP, Tiley EH, Deluca JA. Hand-assisted laparoscopic splenectomy. Surg Laparosc Endosc 1995;5:463-7.

12. Tanimura S, Higashino M, Fukunaga Y, Osugi H. Laparoscopic gastrectomy with regional lymph node dissection for upper gastric cancer. Gastric Cancer 2003;6:64-8.

13. Joensuu H, Fletcher C, Dimitrijevic S, Silberman S, Roberts P, Demetri GD. Management of malignant gastrointestinal stromal tumours. Lancet Oncol 2002;3:655-64.

14. Kwon SJ, Korean Gastric Cancer Study Group. Surgery and prognostic factors for gastric stromal tumor. World J Surg 2001;25: $290-5$. 